\title{
Davidson, Interpretation and First-Person Constraints on Meaning ${ }^{1}$
}

\author{
Barry C. Smith
}

\begin{abstract}
Donald Davidson's account of meaning and mind is thought to be overly thirdpersonal. Its interpreter-relative treatment of thought and language neglects the contribution that first-personal and sub-personal aspects of a speaker's competence make to the significance of speech. However, Davidson's own work contains materials that point towards a more speaker-centred account of meaning. I shall argue that by adding experience to Davidson's scenario of triangulation we can bridge the publicly interpretable content of a speaker's utterances and the immediate first-person accessibility they have to the speaker.
\end{abstract}

Keywords: interpretation; meaning; publicity first-person knowledge; rule-following; triangulation

[W]e all talk so freely about language or languages that we tend to forget that there are no such things in the world; there are only speakers and their various written and acoustical products. This point, obvious in itself, is nevertheless easy to forget, and it has consequences that are far from universally recognised.

(Davidson, 1992: p. 256)

What is it for a speaker to mean something by the sounds he emits? A natural answer is that the sounds uttered belong to the sound patterns of a common language: a language the speaker shares with others. But for those who, like Davidson, do not recognize the existence of common languages, a different answer must be given. The question is pressing since all that is acknowledged is speakers and their 'various written and acoustical products', and speakers themselves are unlikely to offer much insight into what they do. As far as most speakers are concerned, they just open their mouths and the words come out in the right order. The words they use are so familiar that they cannot use or hear them without their having the

International Journal of Philosophical Studies

ISSN 0967-2559 print 1466-4542 online (C) 2006 Taylor \& Francis

http://www.tandf.co.uk/journals

DOI: $10.1080 / 09672550600868709$ 
meanings they ordinarily have for them. So where should we look for an account of a speaker meaning something by the sounds he emits?

According to Davidson, an account can be given from the point of view of the radical interpreter. An interpreter has the task of constructing a theory that makes best overall sense of the speaker's behaviour, linguistic and otherwise, in rational terms. In the radical case, the interpreter has no prior understanding of what the speaker says: the 'evidence must be of a sort that would be available to someone who does not already know how to interpret utterances the theory is designed to cover' (Davidson, 1984: p. 128). And the theory must make 'no essential use of unexplained linguistic concepts' (p. 176). The linguistic part of interpreting a speaker's behaviour is undertaken by constructing a recursive truth theory for his sentences along the lines Tarski proposed for constructing definitions of truth for formal languages. The radical interpreter's knowledge of what the speaker's sentences mean is encoded by T-theorems of the form

(T) $\Sigma$ is true - in - L iff $p$,

where ' $\Sigma$ ' is replaced by a structural description of a speaker's sentence and ' $p$ ' is replaced by an interpreter's sentence with the same truth-value. A correct theory of truth will be one that states the conditions under which the sentences uttered by the speaker are true. By stating the conditions of truth for each sentence, the theory provides a way to give the meanings for all sentences that belong to what, from a theoretical point of view, could be called his language, or idiolect. The theory of truth thus serves as a theory of meaning for the speaker's utterances, and the interpretations placed on his words are part of a larger project of making sense of his behaviour in the light of further attitudes and actions that there are reasons to ascribe to him.

The radical interpreter only has the evidence of the speaker's behaviour and the surrounding circumstances to go on. However, his pronouncements go well beyond the evidence given. Use of a truth theory to interpret linguistic behaviour as intelligible speech must effect transitions from bare descriptions of the audible sounds a speaker produces to semantically revealing descriptions that assign meanings to his words and sentences. And it is in the course of making these transitions that linguistic constructs are introduced:

in passing from a description that does not interpret ... to interpreting description ... we must introduce a machinery of words and expressions (which may or may not be exemplified in actual utterances).

(Davidson, 1984: p. 126)

The resulting conception of the speaker's language as seen through the lens of a theory is the product of radical interpretation not the object of it. ${ }^{2}$ It is 
a theoretical conception of a language: something that gradually comes into view as the radical interpreter makes more and more headway in making sense of a speaker's utterances as semantically significant. However, to achieve this goal the theorist must show how every instance of (T) can be proved using the resources of the theory. This is achieved by discerning a system or pattern in the speaker's linguistic behaviour. From the point of view of the theory:

We want to see the content we attribute to foreign sayings as determined by the contributions of distinguishable parts or aspects of foreign utterances, each of which may occur, making the same contribution, in a multiplicity of utterances. This is secured by having theorems deducible ... from axioms which deal with simple expressions and figure as premises in the deduction of the appropriate theorems for any sentence in which their expressions occur.

(McDowell, 1980: p. 121)

The radical interpreter has to postulate (finitely many) axioms dealing with each of the semantically relevant expressions the theory discerns in L-sentences by means of suitable syntax, together with axioms that describe the semantic upshot of combining those expressions in syntactically legitimate ways. How do we arrive at the set of axioms from which to derive all the T-sentences of what we are calling the speaker's language or idiolect? Which are the semantically relevant parts in any given utterance, and what features must we assign to those parts in order to make the truth theory work? Moreover, how can we be sure that the theory deployed by the radical interpreter postulates the right semantic structure for the speaker's sentences and the right semantic properties for the parts? Answers to these questions depend, in part, on the theorist finding system in the pattern of linguistic behaviour the speaker exhibits.

The choice of axioms and the workings of a theory of truth impose a structure on the speaker's language. The choice of axioms is not independent of the empirical considerations used to confirm a truth theory as interpretative of the L-speaker's utterances. But what empirical evidence should we appeal to in order to confirm a candidate truth theory for a language?

Our initial data are the sentences of the language in question and the truth-values speakers of that language take their sentences to have under certain circumstances. Thus T-sentences are the test bed of a theory of truth and are required simply to pair sentences of the object language with sentences of ours alike in truth-value. Thereafter we have to discover or impose a structure on sentences that treats them as comprising parts that make a repeatable contribution to determining the truth conditions of whole sentences in which they occur. 
We need to know under what conditions speakers take their sentences to be true, and then work out for the small sample of sentences in question how they come to have the truth conditions speakers take them to have on the basis of their distinguishable parts and their syntactic combination. From that point, we can use the assumption of system to generate new sentences and assign them truth conditions that we hope to confirm by finding that speakers of the language hold the new sentences true under the conditions we have assigned to them in the truth theory. We need to find out which assignments of structure to sentences and semantic properties to their parts could have resulted in the distribution of truth-values we find among the sentences in question. In this way, the radical interpreter will come up with a theory of interpretation for the speaker's utterances.

The key issue is whether the meanings the theorist assigns to the speaker's words and sentences are the meanings the speaker attaches to those words and sentences. Is there a more direct account of a speaker's first-personal knowledge of language that can account for how linguistic meanings are consciously apprehended by speakers and recognized to be in play in the speech of others? Surely we want the meanings the theory assigns to a language to be what speakers and hearers of that language would take those words to mean.

However, by assuming the third-person perspective to be that of a theorist, Davidson neglects the ordinary, and still third-personal, perspective of hearers who take themselves to know what others mean without recourse to a truth theory. Davidson of course acknowledges that the point of the radical interpreter's project is 'not to describe how we actually interpret [one another], but to speculate on what it is about thought and language that makes them interpretable' (Davidson, 1995: p. 10). The ordinary interpreter is not a theorist of interpretation. Nevertheless, the point of the theory of interpretation is to render theoretically explicit what the ordinary interpreter could know, which meanings he could justifiably ascribe to a speaker's words, on the basis of the speaker's behaviour, however he comes up with his interpretation.

Another complaint about the radical interpreter's exclusive focus on the speaker's linguistic behaviour is that it neglects the first-person perspective of the speaker: something we recognize in our own experience as speakers; an immediate first-person awareness of what we mean in speaking as we do. In this way, Davidson's third-person epistemology of meaning appears to leave no room for the perspective of either speaker or hearer. Instead, Davidson attempts to capture what it is for a theorist to understand the language. But now the worry is that without some account of the understanding a speaker has of what he is up to and what he takes himself to be saying, the radical interpretation project will be unable to do justice to the phenomena we wanted illuminated in the first place: namely, people's meaning something by the sounds they produce and respond to. The danger 
is that if theoretical assignments of meaning are imposed on speakers' expressions, the meanings assigned may come apart from the meanings speakers take their expressions to have. Thus the theory may give justifiable construals of the sounds a speaker utters but conflict with the interpretations the speaker himself would give to his words.

The worry is familiar enough, but what is less often discussed is the resources Davidson has to counter such objections; and, more surprisingly, the clues his own work gives about how to fill the gaps just mentioned.

The project of the radical interpreter does place an important thirdpersonal constraint on the meanings we can attach to a speaker's words. And although I believe that Davidson seriously underestimates the contributions that first-personal and sub-personal aspects of a speaker's competence make to the linguistic significance of his speech, I think that he does try, in discussions of triangulation, to offer a more speaker-centred account of the speaker's capacity to mean something by his words. I shall say something about the missing sub-personal contribution in what follows, but I want to focus more on an experiential understanding of the first-person perspective which I shall argue plays a fundamental role both in a speaker's meaning something by what he says and in his understanding of others. I shall also show how Davidson's own work provides pointers to such an account.

\section{Third-Personal Accounts of Meaning}

When taking Davidson to task for giving a third-personal and interpreterrelative account of linguistic meaning, we should remember that most philosophical theorizing about language has tended to focus exclusively on the outer dimension of speech. The usual approach is to imagine a theorist observing the linguistic behaviour of members of a given community, from the outside, and trying to figure out what meanings to assign to their words and sentences on the basis of their utterances and the prevailing circumstances. And of course Davidson's Radical Interpreter and Quine's Radical Translator serve as paradigm examples of such theorists. These accounts make no room for the speaker's inner comprehension of speech: the conscious linguistic experience we all have in speaking and listening. Such first-person phenomena, even if admitted, could play no role in theoretical accounts of meaning that take as data purely third-personal observations of linguistic behaviour. Thus an exclusively third-personal focus on the linguistic community's practice does not simply overlook a central feature of speakers' experience; rather the conscious phenomena of speech are discounted on principled grounds as playing no role in linguistic theorizing.

How, it will be asked, could evidence about speakers' immediate awareness of what they mean be taken into account in assigning the correct meaning to people's words? We have no access to a speaker's experiential states, 
and so no evidence of their inner comprehension. Of course, a speaker could study her own language from the first-person perspective, relying on the immediate meaningfulness her speech has for her. But such an account would lack a virtue of these accounts: namely, the attempt to cast light on meaning without presupposing the notion in the course of theorizing.

Another reason to discount the first-personal dimension of meaning would be that it contained nothing of relevance beyond what we communicate to others: what we mean when we speak is what we try to make available to others with whom we communicate. So no part of an expression's meaning can

contain anything which is not manifest in the use made of it, laying solely in the mind of the individual who apprehends that meaning.

(Dummett, 1978: p. 216)

If the meanings people attach to their words were items residing solely in the minds of individuals, there would be no knowing for sure what anyone meant by their utterances. Working out what others mean would be, as John McDowell insists,

a mere matter of guesswork as to how things are in a private sphere concealed behind their behaviour.

(McDowell, 1981: p. 225)

Such a picture is utterly hopeless, running counter as it does to our everyday experience of understanding one another. It also puts at risk the possibility of interlocutors ever addressing the same subject matter. For this reason, McDowell and many others conclude that

the significance of others' utterances in a language must, in general, lie open to view, in publicly available facts about linguistic behaviour in its circumstances.

(McDowell, 1981: p. 314) ${ }^{3}$

The general conclusion from this line of reasoning is that

when we want to understand meaning and communication we should not turn inward, towards mental states, but outward, to what is publicly observable.

(Follesdal, 1990: p. 98) 
Quine (1960) offers a very clear example of this, and draws appropriate morals, telling us that meaning can only be as determinate as translation between languages. The choice of a translation manual for a language is fixed by the totality of behavioural evidence available to a field linguist with no prior knowledge of the language in question. All that the field linguist can glean from observing the behaviour of native speakers in observable circumstances is all there can be to the linguistic significance of the words the native speakers use.

Davidson too subscribes to the public nature of meaning, and like Quine takes this view to have consequences for the indeterminacy of meaning and reference:

The semantic features of language are public features. What no-one can, in the nature of the case, figure out from the totality of the relevant evidence cannot be part of meaning.

(Davidson, 1984: p. 235)

As these quotations show, Davidson and Quine are not merely content to demonstrate how one could know what a speaker means on the basis of observing his linguistic and other behaviour: as if it were one way among others. They are making much more fundamental claims about the nature of meaning. Quine points out that 'radical translation begins at home', and Davidson insists that 'All understanding of the speech of another involves radical interpretation' (1984: p. 125). Each thinks that there is no more to meaning than we can learn from the epistemology of meaning they provide. The knowledge of meaning they are concerned with is the knowledge a theorist has on the basis of observing behavioural evidence about a speaker. And from these conditions under which knowledge of meaning is possible we are meant to reach conclusions about the conditions under which meaning is possible. Thus their epistemology of meaning is meant to tell us something about the nature of meaning itself: what meaning must be like in order to be known. In this way metaphysical conclusions are drawn from epistemological premises. ${ }^{4}$ For both Davidson and Quine, the third-person epistemology of meaning leads to the claim that meaning is an essentially public and social phenomenon. ${ }^{5}$

A common motivation for these views comes from the work of the later Wittgenstein. His stand against the possibility of essentially private meanings, his view that nothing is hidden and his characterization of meaning as use have helped to shape a widely accepted doctrine about the public nature of language. And it is the prevalence of this doctrine that has led to the exclusion of accounts of linguistic meaning giving priority to the first person. However, the reasons advanced in favour of publicity do not, as I shall 
argue, rule out all first-personal accounts of meaning. First let us examine the publicity claim a little further.

\section{The Publicity of Meaning}

My meaning something by my words cannot be an essentially private affair. In so far as I succeed in communicating linguistically with others, they know what I mean. Success depends on this, and it is because people know what speakers mean by their words that linguistic meaning can play the role it does in facilitating communication. What is more, the retreat to the inner, a realm of incommunicable and private meanings, is unsustainable for reasons that Wittgenstein advanced and that I cannot rehearse here. What those considerations come to is the claim that one cannot by oneself stabilize the meanings one attempts to confer on one's words because one cannot establish, at a moment, by some inner ceremony, a semantic standard for the correct application of a word by reference to which all future uses of the word are either correct or incorrect whatever one thinks about its application. Rejection of wholly subjective or private meanings for our words leads us to a publicity of meaning thesis which we can state as follows:

(P) All a person can mean by her words is all she can be known to mean. ${ }^{6}$

Thesis $(\mathrm{P})$ provides a minimal constraint on the notion of meaning: it rules out the possibility that people attach entirely subjective meanings to their words, and provides a role for others to play in a speaker's meaning anything at all. However, the minimal understanding of publicity requires only that it is possible to know what other people's words mean it does not speak of them being publicly displayed in facts about linguistic behaviour. This stronger reading of publicity is often run together with the insistence on meaning being available to others, as some of the quotations above show. But the constraint in $(\mathrm{P})$ says nothing about what makes the meanings of my words available to others; a fortiori it does not say that it is due to meaning's being present on the surface of speech.

So what generates this stronger reading of publicity? We begin with the idea of it being possible to know the meanings of other people's words, and advance from there to a reading of the publicity of meaning thesis according to which the meaning of people's words must be located on the surface of their speech. Let us call this the exteriorizing move. The question to ask is whether denying the essential privacy of meaning requires this stronger reading of publicity; whether, that is, the exteriorizing move is warranted. There would be reason for endorsing the exteriorizing move if failure to endorse it left one with no alternative but the hopeless picture according to which the 
significance of another's words were a matter of mere guesswork as to how things stand in a private sphere. If the move to make meanings public by locating them on the surface of speech represented the only escape from psychologism, then we would be forced to locate linguistic significance in speech behaviour. But so far it has not been established that this thesis does represent the only escape from the psychologism of the hopeless picture.

Arguments for the stronger reading can be found in Quine and in the other authors cited above. They usually hinge on the assumption that if meanings were not located in the public sphere, did not supervene on what is found in the public sphere, or could not be reconstructed from what is found in the public sphere, there would be no knowing for sure what someone else meant. Quine famously remarks:

Language is a social art which we all acquire on the evidence solely of other people's overt behaviour under publicly recognizable circumstances.

(Quine, 1969: p. 26)

The remark may taken as one way to construe Wittgenstein's claim that meaning is use. Certainly Quine accepts - along with Davidson, Dummett and McDowell - that meaning cannot transcend use. But the stronger conclusion - that facts about linguistic significance are to be located in the public sphere - requires further argument. The argument Quine gives starts from the idea that observable behaviour in observable circumstances is all we have to go on in acquiring language from our surroundings, so any appeal to meaning facts must attempt to locate them in what we display to others in our observable behaviour in those circumstances. Of course, we may wonder whether the behaviour of others is all we have to go on in learning a language, and why, even if this were the data, it would follow that the linguistic facts we come to know could be found among, or reconstructed from, that observable behaviour. ${ }^{7} \mathrm{He}$ tells us that:

In psychology one may or may not be a behaviourist, but in linguistics one has no choice.... We depend strictly on overt behaviour in observable circumstances.... There is nothing in linguistic meaning beyond what is to be gleaned from overt behaviour in observable circumstances.

(Quine, 1990: pp. 37-8)

But this view commits us to a mistaken view of language acquisition. It presumes that the child learning a language and the theorist of language are in the same predicament, facing the same task and subject to the same 
evidential constraints. But this is false. The linguist, unlike the child, is not trying to acquire the language by observation of the data, but trying, rather, to explain how the child could have acquired her linguistic competence on the basis of the evidence she was exposed to. The linguist attempts this on the basis of specific hypotheses about the information the child is innately endowed with that would enable her to map a particular course of linguistic experience on to an elaborate ability to assign complex syntactic structures to the sounds she produces and responds to: structures that go well beyond the data.

The problem, then, is to determine the innate endowment that serves to bridge the gap between experience and knowledge attained.

(Chomsky, 1986: p. 38)

The special, dedicated component that enables the normally functioning infant to acquire one of the possible human languages on the basis of exposure to a course of experience is the language faculty. According to Chomsky, this is a component of the mind/brain with which humans are uniquely endowed. And so far it offers the only worked-out proposal about how humans acquire grammatical knowledge of their first language. The forlorn idea that we learn syntactic structure by analogy with the repetitious learning of a manual skill is a non-starter and does not merit serious discussion. There is no evidence that such repetitive practice takes place or that mistakes of the kind expected in such training actually occur. What needs to be explained, instead, is why a speaker who has had exposure to a limited set of utterances can produce indefinitely many new ones and 'distinguish a certain set of "grammatical" utterances, among utterances that he has never heard and might never produce', and in doing so 'projects his past linguistic experience to include certain new utterances and exclude others' (Chomsky, 1955: p. 61). The competence acquired by the child goes far beyond the linguistic evidence she is exposed to, and poverty-of-stimulus arguments show that generalizations about syntactically permissible structures of the adult language cannot be formed from the paucity of the data available to the child. ${ }^{8}$ However, a sub-personal mechanism that projects in accordance with the innate principles of grammar would explain how this is possible. And inference to the best explanation - in this case the only explanation - suggests that we should accept the linguist's postulation of an innate language faculty. Thus, the response to Quine is that behavioural evidence is not the only basis - and could not be the only basis - on which the child acquires a richly syntactically structured language that obeys universal principles of grammar. It also suggests that the child and theorist are not in the same predicament. The child is not forming hypotheses about the properties of the language faculty that enable her to acquire a grammar 
of her language. She is simply exposed to linguistic data that trigger the setting of certain parameters of permissible variation left open by the universal grammar characterizing the initial state of all language users. Likewise, the linguist is not limited to the behavioural evidence that confronts the child. Evidence about the acquisition of language by speakers exposed to quite different ranges of behavioural data can still bear on a theory of how this child acquires language.

\section{Against the Publicity of Syntax}

To what extent can one consider syntax a property of either the public sphere or one's first-person awareness of linguistic content? Consider the following:

(1) Mary expects to feed herself.

(2) Mary expects the woman sitting up in bed to feed herself.

(3) I wonder who Mary expects to feed herself.

In (1), we take the reference of the reflexive pronoun 'herself' to be to the subject 'Mary'. The reflexive pronoun appears to depend for reference on the nearest noun-phrase which agrees with it in number and gender (cf. 'Mary expects to feed her', where the non-reflexive pronoun cannot depend on a nearby noun-phrase). Thus in (2), the reflexive pronoun depends referentially on the noun-phrase 'the woman sitting up in bed'. However, in (3), the reflexive pronoun 'herself' does not referentially depend on 'Mary', and speakers never assume that it does; although they may not know why. How are speakers able to know these facts? The relevant generalizations are expressed in linguistic terms that are not consciously accessible. The linguistic facts in question are best explained in terms of the underlying structures assigned to expressions by speakers: structures that are not carried around as sentences from one speech episode to another but generated in response to sounds they encounter and derived from interacting principles which govern the syntactic relations of the lexical items they deploy in particular combinations. On this account, language, or at any rate syntax, is seen as a fully internalized module of the mind. No radical interpreter or translator will get the facts right until he discovers an explanatorily adequate syntax for the speaker: one that explains both how the speaker could acquire his grammar and what he shares with all other human language users.

While Quine's views may be wrong about syntax, his insistence on what is observable places useful stress on the publicity of lexical meaning. Were meanings not publicly available, and recognizable from observable use of expressions, communication could not succeed. But once again, this only takes care of one side of the communicative exchange. We need to augment 
the third-personal viewpoint on others using a language with the speaker's own point of view. After all, speakers don't just use words, they understand them. So what, then, is Quine's view of understanding? Well, even this is to be accounted for solely in terms of use:

understanding a word consists in knowing how to use it in sentences and how to react to such sentences.

(Quine, 1990: p. 58)

Is this enough? Certainly, the behaviour which speakers exhibit in language use may be a guide to their understanding, but it cannot constitute their understanding. Knowing what a word means is not just having an ability to use and react to it, unless, of course, use abilities have insides as well as outsides. ${ }^{9}$ Behaving in certain ways cannot constitute, they can only reflect, our knowledge of what we mean by our words. The moral is that outer states stand in need of inner experiences.

We need an account of understanding a language in which what it is to understand a language is (at least) to understand words of the language and the way they can be legitimately combined to perform speech acts of various kinds with particular contents. This requires knowledge of syntax and knowledge of semantics. Knowledge of syntax is less problematic. Knowledge of semantics, or at any rate knowledge of word meaning, is highly problematic. How does an account of what I mean by my words serve in an account of communication with you? Accounts restricted to what gets communicated tend to leave out what it is for you and me, comprehendingly, to mean what we do by the words with which we communicate.

We need an account of linguistic meaning that does justice both to its inner and its outer dimensions. So in any adequate account of our dealings with language, a way must be found to restore the first-person point of view of the language user, and to reconcile what is immediately available to speakers in their inner acts of comprehension with what is outwardly accessible in their public practice and observable speech. Notice, however, that if we accept the exteriorizing move that comes with the stronger reading of publicity, the reconciliation between inner and outer becomes particularly acute: for how can meaning be part of the mind of the speaker if it also lies open to view on the surface of linguistic behaviour?

\section{Is There a Tension between Publicity and First-Person Knowledge of Meaning?}

Already it may appear that the public side to mind and meaning threatens the possibility of linguistic and psychological self-knowledge. But appearances to the contrary, the external dimension actually ensures that 
whether a subject is in a given mental state or means such and such by his words is an objective matter, answerable to more than just the subject's own opinions. Thus the possibility of third-person knowledge serves as a requirement on a satisfactory account of first-person knowledge: it is why states that are immediately available to us as part of our inner world can be credited with an objective reality over and above our immediate impression of them. The hard problem is explaining how one's immediate impressions (of how things seem to one) can amount to knowledge of objective, empirical facts - one's being in certain publicly determinable states of mind, or one's uttering words with publicly interpretable meanings.

The problem arises when we try to square this objective and outward aspect of the mental [and the meaningful] with the special way in which we know our own minds [and meanings] from the first-person perspective. How can states whose natures belong partly in the public sphere be so readily available to us from the first-person point of view?

(Smith, 1998: p. 392)

We are inclined to think of what we mean and think as being automatically available to us as part of our inner lives. But now we see the other half of the problem:

How can the facts of mental life [including knowledge of meaning] be part of the inner world of a subject if they are also objective facts knowable by others on the basis of outwardly observable behaviour?

(Smith, 1998: p. 392)

The answer is that interpretation and the first-person perspective are conjoint. The existence of a third-person perspective, that of an informed interpreter, secures a certain objectivity for claims about the details of a person's language. There being facts to be known from the interpreter's point of view means that there are facts for the person to get hold of from the first-person point of view. But what a fully satisfying account of our firstperson knowledge of meaning has to explain is why opinions about what we mean, not arrived at by interpretation (i.e. not theoretically generated), nonetheless coincide with how we can be interpreted by others (i.e. with the pronouncements of interpretation theory). The only way to explain this, I shall argue, is to acknowledge the role the first-person perspective plays both in a speaker's meaning something by what he says and in his understanding of others. 


\section{Davidson and Wittgenstein on Following a Rule}

So far I have stressed the importance of Wittgenstein's thinking to the emergence of the publicity thesis, but it is important to remember that Wittgenstein himself never lost sight of the felt tension between the firstand the third-person perspectives, or of the need to reconcile them. At $\$ 138$ of Philosophical Investigations, where he has been stressing the phenomenon of the meaning of a word coming to mind all at once, he asks: how can meaning be all there at once in the mind of a speaker if it is also the unfolding of use through time? A solution to this question was never given, but the materials for a solution lay in resolving the issues that come up under the head of the rule-following considerations. For if the use of expressions in the language were governed by rules, and individuals were capable of following rules, then individuals could be said to grasp the rules that dictate a pattern of use. The trouble is finding a suitable item to serve as the candidate piece of knowledge that informs the speaker what the rule requires of him on any particular application. Wittgenstein tells us which explanations won't serve, but he offers nothing substantial to cast light on what this knowledge does consist in. What matters for our purposes, however, is to note that for all his insistence that meaning is use and nothing is hidden, he did think it necessary to address the issue of how an individual speaker is capable of participating in the rule-governed practice that amounts to using a language.

Part of Wittgenstein's problem arises because he conceives a language as something that extends beyond the speaker, as something the speaker must somehow get hold of. By contrast, the words of Davidson with which this article began remind us of how firmly he held the view - which some believe emerged only late in his thinking - that there is no such thing as language, at least if language is conceived as a social practice shared by speakers of a given community. Davidson's picture is altogether different. Words do not carry their meaning from one occasion to the next, nor do they provide a common currency that several speakers can trade on. Instead, meaning is made on each occasion of utterance, in an act of interpretation, by how we understand others' utterances and how we intend our utterances to be understood. All there can be is particular uses of 'written or acoustical products', and our meaning something by them is a matter of how we can be interpreted and how we intend to be interpreted on those occasions. Davidson regards this insight as due to Quine, and he takes it to be Quine's way of interpreting Wittgenstein's dictum that meaning is use.

This is a far cry from Wittgenstein's own way of understanding the claim, and from the way it is usually interpreted. And it is instructive to see the way such different construals of meaning as use play out in the philosophies of Davidson and Wittgenstein. But in spite of their differences both philosophers do aim to cast light on the question: what is it for a speaker to mean 
something on an occasion by the sounds he utters? And both give answers that commit them to the essentially public nature of linguistic meaning.

Wittgenstein's answer is that a speaker means something by his 'written or acoustical products' when his use of these signs or sounds belongs to a social practice: a practice the individual cannot sustain in isolation, and which is shared with other members of his linguistic community. These are rule-governed practices, and what it is for an individual to mean something by producing sounds is a matter of what it is for the individual speaker to be following particular rules of the practice. The set of rules for the use of words (and the combination of words) enshrined in the practice of the linguistic community determines a shared, public language.

By contrast, Davidson thinks that there is no such thing as a language, conceived as a shared set of public practices, and no rules or conventions for speakers to subscribe to. ${ }^{10}$ Davidson's lesson in 'A Nice Derangement of Epitaphs' (1986) was that even if it were possible to specify a full set of rules governing a language, speakers could depart from them and still be understood. Davidson does think that meaning is publicly determined in a social setting, but that it cannot rely on, let alone be constituted by, a social practice. But without Wittgenstein's notion of rules and language, what does Davidson have to offer to explain a speaker's meaning something on an occasion by the sounds he utters?

It may be thought that Davidson has nothing to say about the speaker's predicament or about how an individual comes to qualify for the interpretations a radical interpreter gives to his utterances. But this isn't so. In the later work, Davidson does attempt to say what it is about a speaker that enables him to sustain interpretations of his sounds as utterances of meaningful sentences. This is Davidson's discussion of triangulation: a basic setup for communication where two speakers are responding to a common object or event and to each other. ${ }^{11}$ Here, Davidson gives a partial account of what it is that makes thought and language possible for an individual; an account that focuses on the early learning situation of the child and the parent or teacher. The set-up has two speakers triangulating. In a case of triangulation, the child responds to objects and events while also reacting to the parent or teacher's responses (grouping them as similar) to the same objects and events. And in similar fashion, the parent or teacher responds to the objects and events the child responds to while reacting to the child's responses to those same objects and events. Because they have common objects to respond to, each's response comes to be about something in shared public space and not a response that can be drawn more peripherally or proximally in terms of each's sensory stimulation. For they could not be reacting to each other's responses to internal sensory stimulations. The fact of a common object of attention makes it the case that they are entitled to take each other's responses to be about the same thing, an object thought or talked about. Thus Davidson sees the possibility of thinking or talking about 
the world as depending on the existence of another with whom one shares the set-up for triangulation. Triangulation also provides a basic platform for re-establishing a shared understanding when communication breaks down.

\section{Davidson and Language Acquisition}

It is interesting to note that in the absence of a shared language, triangulation is meant to do for Davidson what rules and rule-following are required to do for Wittgenstein - although the latter sees the speaker as connecting not just with another but with an extending and continuing practice that constitutes a shared language. Each appeals to his account to explain what it is for a speaker to mean something by the words he uses on a particular occasion. Wittgenstein's account explains what goes on there as part of a pattern that includes this and many other examples. Davidson sees the single case as part of a more widespread ability to make sense of ourselves and others from one action to the next. But if triangulation is to offer the alternative to Wittgenstein's rule-following account, it must also deliver, albeit in a different way, a similarly comprehensive account of the phenomena of meaningful speech. And whereas Wittgenstein does consider the first-person perspective of the language user (and struggles to reconcile it with the third-person point of view), Davidson's triangulating subjects are offered no such perspective or outlook on what they are doing. When Wittgenstein has the speaker ask 'What does the rule require of me here?', Davidson simply has each subject make similar responses to the behaviour of the other. Somehow this puts his triangulating subjects in a position to take advantage of their situation, to become thinkers or language users, but we are never told how this is possible for them. Being part of a triangulation, a largely behaviourist affair, is at most a necessary condition for thought and language. What is needed, it seems, is to exploit the experiential insides of the triangulating subjects. Davidson could see no way to do so given how wary he is of the notion of experience and the fact that he makes no room for it in his philosophy of mind. And yet, if we take the experiencing subjects to be jointly attending to the object on which they correlate their responses, both to it and to each other, there are more possibilities for a satisfying explanation of how they come to mean something and understand one another. It is particularly important to give a greater role to the perspectives of the agents, since without the appeal to a shared language, triangulation has to bear the greatest weight in Davidson's account of what it is for a speaker to mean something by the sounds he utters. Remember, there are only occasions of use and ways they can be interpreted.

So just what goes on within the individual? What does his own grasp of the meaning of his words consist in? To answer these questions we would have to look to what takes place and what is achieved in the acquisition 
of word meaning by the language learner. And it is here, I think, that we see a reversal of the usual assumption about Davidson's overly thirdpersonal account of meaning and understanding. Instead, he provides a key insight:

Someone who is consciously teaching a beginner the use of a word may think of herself as simply passing on a meaning that already attaches to the word. But from the learner's point of view, the word the sound - is being endowed with a meaning.

(Davidson, 2001: p. 14)

The insight is that for each speaker it is a matter of her investing the item heard with meaning and not simply recognizing a meaning that already attaches to it, let alone something there on the surface of other people's meaningful speech. The coordination of the minds of speaker and hearer, teacher and learner, under conditions of joint attention is what connects the mind of each to the other and ensures that the meaning the individual hearer invests sounds with is tightly connected to, and in that sense utterly dependent on, what is in the mind of the speaker/teacher (and of others too). Coming to mean something is not just a matter of individuals acting in isolation and happening, correctly as it were, to assume that others have those same internal states of significance-investing experiences. They fix meaning together under conditions of joint attention in which the child can check and monitor the gaze of the parent and the object she visually attends to. ${ }^{12}$

\section{First-Person Meaning and the Understanding of Others}

In the actual situation in which I understand another I want to propose that the first-person case - my knowing what I mean by my words - is basic, and that I rely on this knowledge to know what you mean. This is crucial in the order of acquisition:

(A) I take my words to mean such and such.

(B) In hearing the words you utter, I take them to mean what I mean by them.

How can we account for (A)? And how can we account for my entitlement to knowledge of what you mean on the basis of (B)? Is there a satisfactory treatment of the metaphysics and epistemology of meaning that makes the first-person case basic in just this way? I think that there is and that it depends on the following three components: 
(i) an account of what it is for one to take words to mean what they do this requires joint attention and the coordination of experience between child and adult;

(ii) an account of our epistemic entitlement to knowledge on the basis of (B);

(iii) further empirical constraints including syntax.

In (ii) I have to make a transition from I to II:

I I take you to mean $\mathrm{M}$ by your use of $\mathrm{W}$.

II You mean $\mathrm{M}$ by your use of $\mathrm{W}$.

How can we make a warranted transition from I to II? The answer is that the move from I to II would be justified by III:

III $\mathrm{M}$ is what anyone who uses $\mathrm{W}$ means by it.

But what justifies one in accepting III? It seems that it is only if I had safely made transitions from I to II in enough cases that I could inductively conclude that it was safe to accept III. And yet, each inference is risky. So how do I secure any entitlement?

We cannot justify III by instances of justified transitions from I to II. Yet there is no way to rely on the move from I to II without III. How can we? It is the acceptance of III that warrants the required transitions, and the first thing to acknowledge is that we do make these transitions. But the thing to see is that our entitlement to III is automatic rather than supported by empirical warrant. It is an assumption we cannot but accept from the outset as our default. Without this presupposition (at least initially) our communicative practices would not succeed. We are so constituted as to start by taking everyone to be just like us in this respect: it is so basic an egocentric outlook that it is not even supported by assumption or inference. This is what we do at first by default. ${ }^{13}$ Instead of arriving at this conclusion by inference I just assume that this is what W means: as if the word had that meaning. As a child I take $M$ to mean W by successfully endowing the sound I'm given with meaning in the presence of a jointly attended-to object. The perceptual experience I have and the coordination of that experience with another mean that when a sound label is introduced with that experience I can attach it to the object jointly attended to: it colours the common or coordinated experience of the object. In this way, the sound label commemorates that experience, and it helps to recreate that experience on another occasion when the sound brings to mind the original object-involving experience. If the child has attached a meaning to that sound in the company of another person, she will, at first, have no reason to distinguish the presence of that sound, whenever it is produced, from the 
meaning the word has for her. And so by default the meaning it has for the child will not be distinguished from the meaning it has for anyone else. (It is often a surprise to the monolingual child to discover that there are speakers who cannot make something of the words she uses.) In this initial phase, every hearing of the word will come with that meaning. And as far as the child is concerned, that is just what the word means. The egocentrism of the child serves her well at first and helps her to understand others on the assumption that everybody is like her in this respect. In the default situation, anyone who uses $\mathrm{W}$ will be taken to mean $\mathrm{M}$ because that is what they will be heard to mean. And as long as the default case is one in which the child stays among people from whom she learned the word (and others with whom they in turn are linguistically close), it will be safe to move from I to II, by means of transitions so automatic they will not even count as inferences.

An analogy that helps here is looking and seeing. Where there is a looking by someone, there is a seeing. I can't have another person's experience of seeing, but if I observe them looking round quickly and I want to know what they saw, I turn round and point my eyes in the direction of theirs (I look there) and I read my experience for theirs. I take myself to be seeing what they are seeing. And so long as we are sufficiently alike, and suitably placed, this will be good enough. There is a similar connection between use and understanding. They usually come together and are so connected that as with looking and seeing we do not even make a conscious inference from one to the other: we treat them as wedded together. But I can only observe your uses of words, not enjoy your experience of understanding. In my own case I simply speak with understanding of what I say; I don't observe my own use. But if, for me, my use of words comes with the understanding they have for me, then whenever I encounter the use of these words, they will be backed by the understanding I have of them. I shall at the outset use my understanding of these words to understand you. (Who else's understanding should I use?)

To flesh out an account of how we come to mean something first-personally, we would need to look at many factors that conjointly influence or constrain the meanings we arrive at. These may be third-person (or at any rate, second-person in the presence of another person) constraints on the emergence or constitution of meaning. But constraints can come from many sources. Some may be endogenous and have as their source not our personal-level thinking and reasoning but our sub-personal system of native endowments. Constraints on what we can mean as we come to use words in sentences may come from syntax and even phonology. Syntax will place constraints on what interpretations particular arrangements of words can and cannot bear: which referential terms depend on others, as in examples (1)-(3) above, what scope certain expression have over others, and so on; and phonology will constrain what range of sounds can count as the 
realization of a word. These constraints operate within individual language users and affect their conscious experience of meaningful speech. Some of them may be factors at work in all language users: that is to say, universal features of the architecture of the human language system. Other constraints will come from our personal level understanding of word meanings and the way we use it to make immediate sense of what others are saying. When this fails us we may resort to interpretation, or we may chose words knowing how our interlocutors but not us will immediately interpret them. At this stage we do become reflective interpreters of others, or, if there is too little to go on, we triangulate with them by our communicative responses. All these factors shape and characterize the conscious experience of language a speaker has in meaning what he does. An investigation of these different aspects of speech may draw on the study of very different aspects of our cognition, or our relation to others. The picture is richer and more elaborate than most philosophers have appreciated; it requires attention to empirical studies, and there is a lot of work still to be done. Davidson has provided a powerful framework for thinking about these issues and pointers to how the story could be developed further. Others will have to take the project forward, but without his contribution we should have had little idea of where to start.

\section{Birkbeck College, University of London}

\section{Notes}

1 A version of this paper was first presented in 2003 to the Philosophy of Language Seminar of the Philosophy Programme in the University of London in honour of Donald Davidson. I am grateful to the audience on that occasion. I am also very grateful to Ophelia Deroy for incisive written comments and suggestions. The ideas developed here were discussed with Donald Davidson and Marcia Cavell on visits to Berkeley, These discussions were always a great source of pleasure and encouragement and I benefited greatly from them; though I never budged Davidson an inch in the direction I was recommending. I shall miss that fierce but admonishing stare Davidson would deliver when I had clearly gone too far in departing from his views. His strength of mind and the fundamental way he had of thinking about issues and seeing connections between them will be widely missed, but they will ensure his lasting impact on the subject.

2 The notions of word, word meaning, singular term, predicate, etc. are just theoretical concepts used in the construction of a theory for interpreting a person's speech (see Davidson, 1990: p. 300).

3 Despite important differences, McDowell and Dummett are at one on this point and also close to Quine and Davidson.

4 For a clear and incisive discussion of this point see Pagin, 2000.

5 However, their views about the nature of meaning lead to differences between them in where they locate the facts about meaning. For Davidson, the meanings of people's utterances are a matter of the gloss an interpreter can put on a speaker's linguistic behaviour. For Quine, on the other hand, meaning must be 


\section{FIRST-PERSON CONSTRAINTS ON MEANING}

reconstructed from these behavioural materials. Quine is a behaviourist about meaning, Davidson is not (or not quite). For Davidson linguistic meaning, or rather interpretation, supervenes on behaviour.

6 We should add the qualification 'by individuals suitably equipped to judge with whom she communicates'.

7 In the end, all Quine can reconstruct from the meagre materials of behaviour, physically described, is the notion of stimulus meaning.

8 The generalizations that explain linguistic data can only be characterized at levels of linguistic structure remote from surface form.

9 Dummett, of course, comes close in a number of places to saying that the behaviour is which meaning is manifested amounts to what it is to know the meaning of expressions. However, he also claims that speech is a conscious rational activity and that only those regularities consciously selected count as part of the language. The thought here that abilities may be cognitive abilities with 'insides' as well as 'outsides' is perhaps what Dummett is after when he talks of linguistic abilities as being more than merely practical abilities and as having an ineliminable theoretical component that guides as speaker as to which uses to make of his expressions (see Dummett, 'Language and Truth', in Dummett, 1993: pp. 117-46).

10 'If one speaker is to understand a second [this does] not suggest that the two would need to speak the same language ... it does not involve shared rules or conventions' (Davidson, 1992: p. 260).

11 See Davidson, 1982, 1992, 2001, and Glüer, 2006.

12 For convincing empirical evidence that it is only under these conditions that the infant securely attaches a meaning or a word, see the work of Dare Baldwin (1995).

13 The ideas here concerning our entitlement to knowledge of another's meaning adapts the epistemological framework provided by Crispin Wright in his discussion of Wittgtenstein's On Certainty, in particular the role of hinge propositions (see Wright, 1985 and 2004).

\section{References}

Baldwin, D. (1995) 'Understanding the Link between Joint Attention and Language', in C. Moore and P. J. Dunham (eds) Joint Attention: Its Origins and Role in Development, Hillsdale, NJ: Erlbaum, pp. 131-58.

Chomsky, N. (1955) Syntactic Structures, Cambridge, Mass.: MIT Press.

- (1986) Knowledge of Language, Westport, Conn.: Praeger.

Davidson, D. (1982) 'Rational Animals', Dialectica 36: 317-27. Reprinted in Davidson, 2001, Subjective, Intersubjective, Objective, Oxford: Claredon Press, pp. 95-106.

(1984) Inquiries into Truth and Interpretation, Oxford: Oxford University Press. (1986) 'A Nice Derangement of Epitaphs', in E. Lepore (ed.) Truth and Interpretation, Oxford: Blackwell.

- (1990) 'The Structure and Content of Truth', Journal of Philosophy 87: 279-328.

- (1992) 'The Second Person', Midwest Studies in Philosophy 17: 255-67. Reprinted in Davidson, 2001, Subjective, Intersubjective, Objective, Oxford: Claredon Press, pp. 107-22.

- (1995) 'Could There be a Science of Rationality?', International Journal of Philosophical Studies 3: 1-16. Reprinted in Davidson, 2004, Problems of Rationality, Oxford: Claredon Press, pp. 117-34. 


\section{INTERNATIONAL JOURNAL OF PHILOSOPHICAL STUDIES}

_ (2001) 'Externalisms', in P. Kotatko, P. Pagin and G. Segal (eds) Interpreting Davidson, Stanford: CSLI.

Dummett, M. (1978) Truth and Other Enigmas, London: Duckworth. (1993) The Seas of Language, Oxford: Oxford University Press.

Follesdal, D. (1990) 'Indeterminacy and Mental States', in R. Barrett and R. Gibson (eds) Perspectives on Quine, Blackwell.

Glüer, K. (2006) 'Triangulation', in E. Lepore and B. C. Smith (eds) The Oxford Handbook of Philosophy of Language, Oxford: Oxford University Press.

McDowell, J. (1980) 'Physicalism and Primitive Denotation: Field on Tarski', in M. Platts (ed.) Reference, Truth and Reality, London: Routledge \& Kegan Paul, 1981. (1981) 'Anti-Realism and the Epistemology of Understanding', reprinted in his Meaning, Knowledge, Reality, Cambridge, Mass.: Harvard University Press.

Pagin, P. (2000) 'Publicness and Indeterminacy', in P. Kotatko and A. Ornstein (eds) Knowledge, Language and Logic: Questions for Quine, Dordrecht: Kluwer, pp. 163-80.

Quine, W. V. (1960) Word and Object, Cambridge, Mass.: MIT Press.

- (1969) Ontological Relativity and Other Essays, Cambridge, Mass.: Harvard University Press. (1990) The Pursuit of Truth, Cambridge, Mass.: Harvard University Press.

Smith, B. C. (1998) 'On Knowing One's Own Language', in C. Wright, B. C. Smith, and C. Macdonald (eds) Knowing Our Own Minds, Oxford: Oxford University Press.

Wittgenstein, L. (1953) Philosophical Investigations, Oxford: Blackwell.

Wright, C. (1985) 'Facts and Certainty', Proceedings of the British Academy, 71.

- (2004) 'On Epistemic Entitlement', Aristotelian Society Supplementary Volume LXXVIII: 167-212. 